\title{
Pengaruh Penggunaan Minyak Serai (Cymbopogon nardus L Oil) terhadap Penurunan Intensitas Nyeri Artritis Rheumatoid pada Lansia
}

\section{The Influence Of Cymbopogon Oil (Cymbopogon nardus L) on Elderly's Rheumatoid Arthritis Pain Intensity Reduction}

\author{
Dian Utama Pratiwi Putri ${ }^{1}$, Wayan Sri Astuti ${ }^{2}$ \\ Fakultas Kesehatan, Universitas Mitra Indonesia, Indonesia
}

\section{ARTICLE INFO}

\section{Article history}

Received date

27 Oct 2020

Revised date

06 Nov 2020

18 Nov 2020

Accepted date

30 Nov 2020

Keywords:

Cymbopogon oil;

Elderly;

Pain intensity;

Rheumatoid Arthritis.

Kata kunci:

Minyak serai;

Lansia;

Intensitas nyeri;

Arthritis Rheumatoid.

\author{
ABSTRACT/ ABSTRAK
}

\begin{abstract}
Rheumatoid arthritis is an autoimmune disease and this means joint inflammation. The objective of this research was to find out the influence of Cymbopogon oil (Cymbopogon nardus $L$ ) on the elderly's rheumatoid arthritis pain intensity reduction in Way Panji public health center of Sidoharjo village in Way Panji sub-district of South Lampung in 2018. This was pre-experimental research with one group pretest and posttest design. 67 samples were taken by using stratified random sampling. Data were collected using interviews and observations by using a numeric rating scale (NRS) for pain intensity. The result showed that before and after Cymbopogon oil administration the NRS were 2,87 and 1,37 respectively. The independent t-test result showed rheumatoid arthritis pain intensity differences before and after Cymbopogon oil administration with a t-value of 24.254 and a significance value of 0.000 . This indicated that Cymbopogon oil could be used as one of the alternatives for reducing pain intensity. The conclusion was that there was a significant difference in pain intensity before and after using Cymbopogon oil at rheumatoid arthritis patients in Way Panji public health center of Sidoharjo village in South Lampung (p-value 0,000). The researcher expects this research result can be used as an information source and reference for autonomous intervention for rheumatoid arthritis patients.
\end{abstract}

Arthritis Rheumatoid merupakan penyakit autoimun. Arthritis Rheumatoid secara harafiah berarti peradangan dari satu atau lebih sendi-sendi. Penelitian ini bertujuan untuk mengetahui pengaruh penggunaan minyak serai (Cymbopogon Nardus. L Oil) terhadap penurunan intensitas nyeri pada penyakit artritis rheumatoid pada lansia di Puskesmas Way Panji Desa Sidoharjo. Penelitian ini menggunakan metode pra eksperimen dengan rancangan One Group Pre-test Post-test design, menggunakan stratified random sampling dengan sampel sebanyak 67 orang, pengumpulan data yang dilakukan melalui wawancara dan melalui observasi dengan penilaian hasil ukur menggunakan numeric rating scale (NRS) mean intensitas nyeri sebelum penggunaan minyak serai 2,87 dan setelah dilakukan penggunaan minyak serai 1,37 . Hasil dari penelitian ini didapatkan perbedaan intensitas nyeri arthritis rheumatoid sebelum dan setelah dilakukann penggunaan minyak serai. Ini dibuktikan dengan uji t-dependent didapat nilai t sebesar 24,254 dengan nilai signifikansi=0,000 dengan hasil tersebut penggunaan minyak serai dapat digunakan sebagai salah satu alternative untuk mengurangi intensitas nyeri. Dapat disimpulkan ada perbedaan yang signifikan intensitas nyeri sebelum dan sesudah penggunaan minyak serai pada pasien arthritis rheumatoid di puskesmas Way Panji Desa Sidoharjo Lampung Selatan.

Corresponding Author:

Dian Utama Pratiwi Putri

Fakultas Kesehatan, Universitas Mitra Indonesia, Indonesia

Email: dian@umitra.ac.id

\section{PENDAHULUAN}

Organisasi kesehatan dunia (WHO) melaporkan bahwa 20\%, penduduk dunia terserang penyakit arthritis rheumatoid. Dimana $5-10 \%$ adalah mereka yang berusia 5-20 tahun dan $20 \%$ mereka yang berusia 55 tahun (Wiyono, 2010). Lebih dari 355 juta orang di dunia ternyata 
menderita penyakit arthritis rheumatoid. Itu berarti, setiap enam orang di dunia ini satu diantaranya adalah penyandang arthritis rheumatoid yang mana jumlah penduduk dunia tahun 2012 sebanyak kurang lebih 7 miliar jiwa. Diperkirakan angka ini terus meningkat hingga tahun 2025 dengan indikasi lebih dari 25\% akan mengalami kelumpuhan (Listiyani, 2019).

Jumlah penduduk lanjut usia di Indonesia diperkirakan pada tahun 2010 akan mencapai 23,9 juta jiwa, dan prakiraan pada tahun 2020 jumlah lanjut usia akan mencapai 28,8 juta jiwa (Dermawan, 2012). Indonesia termasuk dalam lima besar negara dengan jumlah lansia terbanyak dengan jumlah 18,1 juta jiwa. Pada tahun 2030 diperkirakan jumlah lanjut usia menjadi 36 juta jiwa (Departemen Kesehatan RI, 2013).

Berdasarkan pusat data Dinas Kesehatan Provinsi Lampung, arthritis rheumatoid merupakan salah satu penyakit terbanyak yang diderita lansia, yaitu pada tahun 2015 sebanyak 118.659 orang $(7,91 \%)$. Hal ini merupakan suatu problem yang harus bisa ditangani oleh pemerintah, karena dengan kondisi lansia yang semakin banyak menderita arthritis rheumatoid. Hal tersebut akan mampu menjadikan lansia menjadi pasif, maka diperlukan dorongan agar lansia tersebut tetap aktif dalam segala hal. Salah satu program pemerintah dalam hal ini adalah pelayanan kesehatan di posyandu, puskesmas setiap daerah, yang diharapkan mampu menstabilkan gangguan kesehatan pada lansia (Dinas Kesehatan Provinsi Lampung, 2015).

Data dari Dinas Kesehatan Kabupaten Lampung Selatan pada tahun 2016 sebanyak 10.001 orang dan Penderita penyakit di kabupaten Lampung Selatan pada tahun 2016 terbanyak pada jenis kelamin perempuan sebanyak 151.104 penderita (53\%) sedangkan pada jenis kelamin laki-laki sebanyak 132.819 penderita (47\%). Berdasarkan pengamatan penyakit berpotensial KLB dan penyakit tidak menular yang diamati di Puskesmas di Kabupaten Lampung Selatan dan jaringannya terdapat suatu pola dan trend penyakit didapatkan 10 besar kunjungan kasus artritis rheumatoid menempati urutan ke 5 dari 10 penyakit menonjol yang ada dengan distribusi kunjungan sebanyak 25.668 orang (Dinas Kesehatan Kabupaten Lampung Selatan, 2017).

Artritis rheumatoid merupakan penyakit autoimun dari jaringan ikat terutama synovial dan kausanya multifaktor. Penyakit ini ditemukan pada semua sendi dan sarung sendi tendon, tetapi paling sering di tangan. Penyakit yang menyerang sendi disebut artritis rheumatoid.
Artritis rheumatoid secara harafiah berarti peradangan dari satu atau lebih sendi-sendi. Penyakit ini dapat menyebabkan cacat sendi. Jenis arthritis rheumatoid yang sering kali dijumpai ada 3 macam yaitu: osteoarthritis, arthritis rheumatoid $(A R)$ dan rheumatoid arthritis gout (Green, 2010).

Adanya nyeri sendi pada penderita arthritis rheumatoid membuat seringkali takut untuk bergerak sehingga menggangu aktivitas sehari-hari dan dapat menurunkan produktivitas (Hardywinoto, 2005).

Berdasarkan data Puskesmas Way Panji Tahun 2017 disebutkan bahwa arthritis rheumatoid merupakan penyakit terbanyak ke tiga, yaitu sebanyak $1.623(14,3 \%)$ penderita. Hasil pra survey pada tanggal 2 April 2018 terhadap lansia dalam kunjungan pasien di Puskesmas Way Panji Kabupaten Lampung Selatan dengan artritis rheumatoid. Pada tahun 2018 jumlah penderita arthritis rheumatoid sebanyak $462(16,02 \%)$ yang diantaranya penderita artritis rheumatoid pada usia muda yaitu sebanyak $331(71,65 \%)$ dan pada lansia sebanyak $131(28,36 \%)$ yaitu pada januari 42 $(9,09 \%)$ penderita, februari $37(8,01 \%)$ penderita, maret $52(11,26 \%)$ penderita.

Salah satu manfaat serai adalah mengurangi nyeri pada persendian. Sifat antiinflamasi dan sifat penghilang rasa sakit dari serai bisa membantu mengobati radang sendi, rematik, osteoarthritis, encok, dan jenis nyeri sendi lainnya. Sifat anti-inflamasi dalam serai membantu menekan aktivitas siklooksigenase-2, enzim yang terlibat dalam peradangan yang menyebabkan nyeri, terutama di sendi (Hafni, 2016).

Penelitian dari The Science and Technology telah menentukan bahwa serai memiliki manfaat antioksidan yang dapat membantu mencegah kanker, dalam serai terdapat kandungan zat anti-mikroba dan anti bakteri yang berguna sebagai obat infeksi serta mengandung senyawa analgetik yang membantu menghilangkan rasa sakit atau nyeri seperti nyeri otot dan nyeri sendi akibat artritis rheumatoid atau anti rematik (Hyulita, 2013).

Berdasarkan data di atas maka penelitian ini dilakukan dengan tujuan untuk mengetahui pengaruh penggunaan minyak serai (Cymbopogon Nardus. L Oil) terhadap penurunan intensitas nyeri pada penyakit artritis rheumatoid pada lansia di Puskesmas Way Panji Desa Sidoharjo. 


\section{METODE}

Penelitian ini menggunakan rancangan analisis dengan menggunakan pendekatan pra eksperimen (Pre-Eksperimental Designs), Adapun rancangannya adalah One Group Pretest Pos-test. Dimana rancangan ini juga tidak ada kelompok pembanding (kontrol). Populasi dalam penelitian ini adalah lansia di atas 60 tahun dengan penderita Artritis Rheumatoid sebanyak 131 lansia di Puskesmas Way Panji Desa Sidoharjo Kecamatan Way Panji Kabupaten Lampung Selatan. Pengambilan sampel pada penelitian ini secara probability sampling dengan menggunakan stratified random sampling jumlahnya 67 responden.

Penelitian ini sebelumnya sudah mendapatkan layak etik dengan dinyatakan layak etik (ethical exemption) dari Komite Etik Politeknik Kesehatan Tanjung Karang dengan nomor 315/KEPK-TJK/X/2020 sehingga terpenuhinya indikator setiap standar.

\section{HASIL}

Tabel 1. Karakteristik Responden

\begin{tabular}{lrr}
\hline \multicolumn{1}{c}{$\begin{array}{c}\text { Karakteristik } \\
\text { Responden }\end{array}$} & n & \% \\
\hline Usia & & \\
$60-69$ & 46 & 68,7 \\
$70-79$ & 11 & 16,4 \\
$>80$ & 10 & 14,9 \\
\hline Jenis kelamin & & \\
Perempuan & 48 & 71,6 \\
Laki-laki & 19 & 28,4 \\
\hline Pendidikan & & \\
Tidak sekolah & 19 & 28,4 \\
SD & 24 & 35,8 \\
SMP & 12 & 17,9 \\
SMA & 10 & 14,9 \\
Diploma/Sarjana & 2 & 3,0 \\
\hline Pekerjaan & & \\
Karyawan & 5 & 7,5 \\
Petani & 48 & 71,6 \\
Pedagang & 11 & 16,4 \\
Dan lain lain & 3 & 4,5 \\
\hline
\end{tabular}

Berdasarkan tabel 1 diketahui bahwa dari 67 responden sebanyak 46 responden $(68,7 \%)$ berusia antara 60-69 tahun, sebanyak 11 responden $(16,4 \%)$ berusia antara 70-79 tahun, sebanyak 10 responden $(14,9 \%)$ berusia $>80$ tahun.

Penderita artritis rheumatoid di Puskesmas Way Panji Desa Sidoharjo Lampung Selatan yang berjenis kelamin perempuan sebanyak 48 responden $(71,6 \%)$, dan yang berjenis kelamin laki-laki sebanyak 19 responden $(28,4 \%)$.
Penderita arthritis rheumatoid yang tidak sekolah sebanyak 19 responden $(28,4 \%)$, yang berpendidikan SD sebanyak 24 responden (35,8\%), yang berpendidikan SMP sebanyak 12 responden $(17,9 \%)$, yang berpendidikan SMA sebanyak 10 responden $(14,9 \%)$, dan penderita arthritis rheumatoid yang berpendidikan Diploma atau Sarjana sebanyak 2 responden (3\%). Penderita arthritis rheumatoid yang bekerja sebagai karyawan sebanyak 5 responden (7,5\%), yang bekerja sebagai petani sebanyak 48 responden (71,6\%), yang bekerja sebagai pedagang sebanyak 11 responden (16,4\%), yang bekerja sebagai buruh atau guru sebanyak 3 responden $(4,5 \%)$.

Tabel 2. Rata-rata Intensitas Nyeri Sebelum dan Sesudah Diberikan Terapi Penggunaan Minyak Serai pada Lanjut usia Artritis Rheumatoid

\begin{tabular}{ccccccc}
\hline Variabel & Mean & Min & Max & SD & SE & $\begin{array}{c}\mathbf{9 5 \%} \\
\text { CI }\end{array}$ \\
\hline $\begin{array}{c}\text { Nyeri } \\
\text { Sebelum } \\
\text { Nyeri }\end{array}$ & 2,87 & 2 & 3 & 0,344 & 0,42 & $\begin{array}{c}2,78- \\
2,95\end{array}$ \\
Setelah & 1,37 & 1 & 2 & 0,487 & 0,60 & $\begin{array}{r}1,25- \\
1,49\end{array}$ \\
\hline
\end{tabular}

Dari hasil analisa pada tabel 2 didapatkan rata-rata intensitas nyeri arthritis rheumatoid sebelum penggunaan minyak serai dengan nilai intensitas nyeri maksimal 3 (4-6 nyeri sedang) dan intensitas nyeri minimal 2 (1-3 nyeri ringan), dengan nilai rata-rata intensitas nyeri yang dialami keseluruhan responden 2,87 (nyeri sedang) dengan nilai standar deviasi 0,344. Berdasarkan nilai rata-rata tersebut dapat kita ketahui tingkat intensitas nyeri yang paling banyak dialami lanjut usia dengan criteria nyeri interval 4-6 atau yang disebut juga dengan kriteria intensitas nyeri sedang. Dengan 95\% tingkat kepercayaan, intensitas nyeri klien sebelum dilakukan pemberian minyak serai sebesar 2,78-2,95 (nyeri sedang).

Didapatkan rata-rata intensitas nyeri arthritis rheumatoid setelah penggunaan minyak serai dengan nilai intensitas nyeri maksimal 2 (13 nyeri ringan) dan intensitas nyeri minimal 1 ( 0 tidak nyeri), dengan nilai rata-rata intensitas nyeri yang dialami keseluruhan responden 1,37 (nyeri ringan) dengan nilai standar deviasi 0,487. Berdasarkan nilai rata-rata tersebut dapat kita ketahui tingkat intensitas nyeri yang paling banyak dialami lanjut usia dengan kriteria nyeri interval 1-3 atau yang disebut juga dengan kriteria intensitas nyeri ringan. Dengan 95\% tingkat kepercayaan, intensitas nyeri klien setelah dilakukan pemberian minyak serai sebesar 1,25 1,49 (nyeri 
Tabel 3. Distribusi Frekuensi Intensitas Nyeri Artritis Rheumatoid pada Lanjut Usia Sebelum dan Sesudah Diberikan Terapi Penggunaan Minyak Serai

\begin{tabular}{|c|c|c|}
\hline Variabel & f & $\%$ \\
\hline \multicolumn{3}{|c|}{ Intensitas Nyeri Sebelum Diberikan } \\
\hline $1-3$ & 9 & 13,4 \\
\hline 4-6 & 58 & 86,6 \\
\hline \multicolumn{3}{|c|}{ Intensitas Nyeri Sesudah Diberikan } \\
\hline 0 & 42 & 62,7 \\
\hline $1-3$ & 25 & 37,3 \\
\hline
\end{tabular}

Dari tabel 3 dapat diketahui bahwa sebelum diberikan minyak serai sebagian besar lanjut usia mengalami nyeri arthritis rheumatoid dengan intensitas 4-6 (sedang) sebanyak 86,6\% sedangkan yang mengalami nyeri arthritis rheumatoid dengan intensitas 1-3 (ringan) sebanyak $13,4 \%$ dan bahwa setelah diberikan minyak serai sebagian besar lanjut usia mengalami nyeri arthritis rheumatoid dengan intensitas 1-3 (ringan) sebanyak 37,3\% sedangkan yang tidak mengalami nyeri 0 (tidak nyeri) sebanyak $62,7 \%$.

Tabel 4. Pengaruh Penggunaan Minyak Serai Pada Lanjut Usia Artritis Rheumatoid

\begin{tabular}{lrrrrr}
\hline \multicolumn{1}{c}{ Variabel } & Mean & Min & Max & SD & 95\% CI \\
Nyeri Sebelum Penggunaan Minyak Serai & 2,87 & 2 & 3 & 0,344 & 1,370 \\
Nyeri Setelah Penggunaan Minyak Serai & 1,37 & 1 & 2 & 0,487 & 1,615 \\
Perbedaan Intensitas Nyeri Setelah Perlakuan & Mean & T & SD & Sig. \\
& 1,50 & 24,254 & & 0,504 & 0,012 \\
\hline
\end{tabular}

Dari tabel 4 dapat diketahui bahwa terdapat perbedaan nilai rata-rata intensitas nyeri sebelum dilakukan terapi penggunaan minyak serai sebesar 2,87 dan setelah dilakukan terapi penggunaan minyak serai terdapat penurunan intensitas nyeri dengan nilai rata-rata 1,37 . Dengan rata-rata perbedaan intensitas nyeri sebelum dan setelah penggunaan minyak serai sebesar 1,50. Sedangkan standar deviasi sebelum dilakukan penggunaan minyak serai yang didapat 0,344 dan setelah dilakukan penggunaan minyak serai standar deviasi 0,487 dengan perbedaan standar deviasi sebesar 0,504 sedangkan nilai $\mathrm{t}=24,254$ dengan signifikansi 0,012 sehingga dapat ditarik kesimpulan bahwa terdapat perbedaan intensitas nyeri arthritis rheumatoid sebelum dan setelah dilakukan pemberian minyak serai. Dapat disimpulkan bahwa ada Pengaruh Penggunaan Minyak Serai Pada Lanjut Usia Artritis Rheumatoid di Puskesmas Way Panji Desa Sidoharjo terbukti dengan nilai $\rho$ value $=0,012(\rho$-value $\leq 0,05)$.

\section{PEMBAHASAN}

Intensitas Nyeri Artritis Rheumatoid pada Lanjut Usia Sebelum dilakukan Pemberian Minyak Serai

Berdasarkan hasil analisa pada tabel 4 didapat rata-rata intensitas nyeri arthritis rheumatoid sebelum diberikan terapi penggunaan minyak serai adalah 2,87 (nyeri sedang) dengan standar deviasi 0,344. Dengan 95\% tingkat kepercayaan, intensitas nyeri klien sebelum diberikan minyak serai antara 2,78-2,95 (nyeri sedang). Dan dapat disimpulkan bahwa sebelum diberikan minyak serai seluruh responden $(86,6 \%)$ mengalami nyeri sedang dan $(13,4 \%)$ mengalami nyeri ringan.

Menurut Smeltzer (2003), usia pertengahan cenderung akan mengalami penurunan aktivitas dan berlanjut sampai tua karena terjadinya penurunan fungsi tubuh akibat proses penuaan. Organ-organ tubuh yang dulunya berfungsi dengan baik tanpa adanya gangguan, sekarang mengalami kemunduran karena dalam proses penuaan.

Hasil penelitian ini mendukung penjelasan di atas yang mana mayoritas lanjut usia yang menjadi responden pada penelitian ini mengalami nyeri arthritis rheumatoid pada daerah lutut yang terdiri dari 37 orang, pada pergelangan kaki sebanyak 27 orang, dan pada bagian pinggul sebanyak 3 orang, sehingga mereka merasa terganggu dalam melakukan aktivitas akibat rasa nyeri, kaku pada sendi, bengkak dan terganggunya fungsi sendi. Selain itu responden perempuan lebih mendominasi yaitu sebesar $71,6 \%$ dibandingkan responden laki-laki sebesar $28,4 \%$.

Secara umum dapat disebutkan seperti terjatuh (accidental falls), cepat letih (easy fatiguability), bingung (acute confusion, nyeri dada (chest pain), mudah sesak kalau beraktivitas, bengkak lengan bawah, kelemahan pada bagian otot tertentu, low back pain, nyeri sendi pinggang, kencing tidak dapat dihentikan, gangguan air besar, sakit kepala (headaches), gatal-gatal (pruritus), dan gangguan tidur (sleep disorder) (Bustan, 2015).

Hal ini sesuai dengan hasil penelitian yang dilakukan oleh Hyulita (2013) yang berjudul 
Pengaruh Kompres Serai Hangat Terhadap Penurunan Intensitas Nyeri Artritis Rheumatoid Pada Lanjut Usia di Kelurahan Tarok Dipo Wilayah Kerja Puskesmas Guguk Panjang Bukittinggi Tahun 2013, yang didapat rata-rata tingkat nyeri sebelum diberikan kompres serai hangat sebesar 4,90 dengan standar deviasi sebesar 1,071 .

Menurut asumsi peneliti, dilihat dari segi jenis kelamin lanjut usia yang menderita arthritis rheumatoid di Puskesmas Way Panji Desa Sidoharjo Lampung Selatan yang terbanyak adalah responden perempuan sebanyak 48 responden dengan proporsi sebanyak $71,6 \%$ dan laki-laki sebanyak 19 orang dengan proporsi sebanyak $28,4 \%$. Laki-laki memiliki sensitivitas yang lebih rendah dibandingkan dengan wanita atau kurang merasakan nyeri. Laki-laki kurang mengekspresikan nyeri yang dirasakan secara berlebihan dibandingkan dengan wanita.

Dilihat dari rentang usia yang biasanya beresiko terkena arthritis rheumatoid adalah usia 60 ke atas, karena kita ketahui sistem metabolisme pada usia tersebut sudah mulai terganggu atau mengalami penurunan fungsi, namun tidak menutup kemungkinan kelompok usia produktif juga mengalami.

\section{Intensitas Nyeri Artritis Rheumatoid pada Lanjut Usia Setelah Dilakukan Pemberian Minyak Serai}

Berdasarkan hasil analisa pada tabel 4 didapat rata-rata intensitas nyeri setelah dilakukan pemberian minyak serai adalah 1,37 (nyeri ringan) dengan standar deviasi 0,487. Dengan 95\% tingkat kepercayaan, intensitas nyeri klien setelah dilakukan pemberian minyak serai antara 1,25-1,49 (nyeri ringan).

Dapat disimpulkan bahwa setelah dilakukan pemberian minyak serai seluruh responden $(62,7 \%)$ tidak mengalami nyeri dan $(37,3 \%)$ mengalami nyeri sedang.

Pada tabel 3 frekuensi intensitas nyeri arthritis rheumatoid sebelum dilakukan pemberian minyak serai $86,6 \%$ mengalami intensitas nyeri sedang (4-6) adalah 58 responden dan lainnya intensitas nyeri ringan (1-3) sebesar $13,4 \%$. Pada tabel 7 setelah dilakukan pemberian minyak serai $(62,7 \%)$ responden dengan sudah tidak mengalami nyeri dan $(37,3 \%)$ dengan intensitas nyeri sedang (4-6).

Berdasarkan tabel 2 rata-rata intensitas nyeri arthritis rheumatoid pre-test 2,87 dengan rata-rata intensitas nyeri post-test 1,37. Dari hasil analisa data penelitian dengan menggunakan uji t-test didapat tingkat kepercayaan sebesar $95 \%$ diperoleh $t=24,254$ dengan nilai signifikan sebesar 0,012. Jadi dapat disimpulkan bahwa penggunaan minyak serai berpengaruh dalam penurunan intensitas nyeri arthritis rheumatoid pada responden lanjut usia di Puskesmas Way Panji Desa Sidoharjo lampung selatan, terbukti dengan nilai $\rho$-value $=0,012(\rho$-value $\leq 0,05)$.

Indikator tunggal yang paling penting dari intensitas nyeri adalah laporan mandiri klien tentang nyeri. Anda bisa mendapatkan laporan mandiri ini dengan meminta klien untuk mengukur nyeri pada skala yang harus mereka bayangkan atau menunjukkan skala yang ada pada klien. Pengukuran nyeri dengan pendekatan objektif yang paling mungkin adalah menggunakan respon fisiologik tubuh terhadap nyeri itu sendiri.

Karakteristik paling subjektif pada nyeri adalah tingkat keparahan atau intensitas nyeri tersebut. Klien sering diminta untuk mendeskripsikan sebagai nyeri ringan, sedang berat. Namun makna istilah ini berbeda bagi perawat dan klien. Skala Numerik (Numeric Rating Scale) NRS, lebih digunakan sebagai pengganti alat pendeskripsi kata. Dalam hal ini, klien menilai nyeri dengan menggunakan skala 0 10. Skala paling efektif digunakan saat mengkaji intensitas nyeri sebelum dan setelah intervensi tarapeutik (Black dan Hawkks, 2014).

Durasi pemberian minyak serai hangat juga mempengaruhi respon nyeri yang dirasakan, dengan kata lain minyak serai diberikan jika toleransi respon fisiologis setiap pasien berbedabeda. Tolrenasi yang dapat diberikan pada seseorang dalam pemberian minyak serai ini yaitu dilakukan selama 20 menit.

Berdasarkan hal tersebut, keseluruhan responden dalam penelitian ini dapat mentoleransi durasi penggunaan minyak serai dengan waktu 20 menit dengan 67 responden.

Dari hasil pengukuran setelah diberikan minyak serai didapatkan hasil bahwa keseluruhan responden mengalami penurunan intensitas nyeri sebesar 1,37 (nyeri ringan), ini dikarenakan lanjut usia yang menjadi sampel sangat kooperatif dan aktif dalam mengikuti petunjuk atau instruksi dari peneliti.

Sifat kimia dalam tanaman serai cymbopogon nardu $l$ ini mengandung minyak atsiri dengan kandungan citral, geraniol, citronellal, methylheptenone, eugenol methyleter, dipenten, eugenol kaninen, kadinol dan limonene. Selain itu, serai juga mengandung alkaloid, flavonoid, dan polifenol. Efek farmakologis tanaman ini yaitu Sebagai obat pengurang nyeri, encok, saraf dan terkilir (Suryo, 2010). 
Penelitian dari The Science and Technology telah menentukan bahwa serai memiliki manfaat antioksidan yang dapat membantu mencegah kanker, dalam serai terdapat kandungan zat anti-mikroba dan anti bakteri yang berguna sebagai obat infeksi serta mengandung senyawa analgetik yang membantu menghilangkan rasa sakit atau nyeri seperti nyeri otot dan nyeri sendi akibat artritis rheumatoid atau anti rematik (Hyulita, 2013).

Menurut asumsi peneliti, mengenai pemberian minyak serai dalam menurunkan intensitas nyeri pada lanjut usia arthritis rheumatoid terbukti dalam mengurangi nyeri yang dirasakan oleh klien. Adanya penurunan intensitas nyeri arthritis rheumatoid setelah diberikan minyak serai ini disebabkan karena

\section{DAFTAR PUSTAKA}

Black, J., dan Hawks, J. (2014). Keperawatan Medikal Bedah: Manajemen Klinis untuk Hasil yang Diharapkan. Dialih bahasakan oleh Nampira R. Jakarta: Salemba Emban Patria.

Bustan, M. N. (2015). Manajemen pengendalian penyakit tidak menular. Jakarta: Rineka Cipta.

Departemen Kesehatan RI. (2013). Prevelensi Lansia. Jakarta

Dermawan, F. (2012). Lansia Masa Kini dan Mendatang. Kementerian Kesehatan.

Dinas Kesehatan Kabupaten Lampung Selatan, (2017). Profil Kesehatan Kabupaten Lampung Selatan. Kabupaten Lampung Selatan.

Dinas Kesehatan Provinsi Lampung. (2015). Profil Kesehatan Provinsi Lampung. Lampung

Green, Wendy. (2010). 50 Hal Yang Bisa Anda Lakukan Hari Ini Untuk Mengatasi Artritis. Jakarta: Gramedia.

Hardywinoto, S. (2005). Panduan gerontologi. Jakarta: PT Gramedia Pustaka Utama.

Hafni, Nur, Aeranie. (2016). Manfaat Tanaman Serai. Jakarta : Gramedia tanaman serai memiliki kandungan minyak atsiri yang dapat mengurangi peradangan pada penderita arthritis rheumatoid, selain itu serai juga memiliki efek farmakologis yaitu Sebagai obat pengurang nyeri, encok, saraf dan terkilir.

\section{SIMPULAN}

Berdasarkan hasil penelitian dan pembahasan maka dapat diambil kesimpulan bahwa terdapat perubahan intensitas nyeri yang berkurang pada pasien athtritis lanjut usia di Puskemas Way Panji Desa Sidoharjo Lampung Selatan setelah diberikan intervensi penggunaan minyak serai.

Hyulita, Sri. (2013). Pengaruh Kompres Serai Hangat Terhadap Penurunan Intensitas Nyeri Artritis Rheumatoid Pada Lanjut Usia Di Kelurahan Tarok Dipo. [Skripsi]. Sumatera Barat: STIKES Yarsi Sumatera Barat.

Listiyani, Y., Indarwati, I., \& Maryatun, M. (2019). PENERAPAN KOMPRES HANGAT DALAM MENURUNKAN SKALA NYERI PADA LANSIA DENGAN REMATIK DI WILAYAH PUSKESMAS NGORESAN KOTA SURAKARTA. Karya Tulis Ilmiah. Surakarta: Program Studi Keperawatan, STIKES Aisyiyah Surakarta.

Smeltzer, C. (2003). Keperawatan Medical Bedah. Jakarta: EGC.

Suryo, Joko. (2010). Herbal Penyembuhan Gangguan Sistem Pernafasan. Yogyakarta: B First.

Puskesmas Way Panji. (2017). Profil Kesehatan Wilayah Kerja Puskesmas Way Panji. Desa Sidoharjo Kecamatan Way Panji. Kabupaten Lampung Selatan.

Wiyono. (2010). Gangguan Psikosomatik Penyakit Rheumatik \& Sistem Muskuloskeletal. Jakarta: FK UI. 